\title{
COMO ESCRIBIR EL ARTÍCULO CIENTÍFICO EXPERIMENTAL Y LA PUBLICACIÓN DE LA TESIS COMO ARTÍCULO
}

\author{
HOW TO WRITE EXPERIMENTAL SCIENTIFIC \\ RESEARCHES AND PUBLISHING THESIS AS AN \\ ARTICLE
}

Recepción: 2020-05-16 - Aceptación: 2020-05-21

\section{Raúl Ishiyama Cervantes ${ }^{1}$}

(iD) ORCID iD 0000-0003-4346-190X

${ }^{1}$ Doctor en Ciencias Biológicas.

No se aprende a investigar memorizando una serie de definiciones, tampoco gracias a leyes, reglamentos o normas que plantean algunos promotores. Se aprende a investigar investigando, practicando; de la misma forma como se aprendió las cosas comunes en el transcurso de la vida, al inicio siguiendo reglas sencillas, revisando los resultados para hacer las cosas cada vez mejor.

La investigación científica experimental, sigue un proceso ordenado de acuerdo al estándar, hablando el lenguaje del mundo científico globalizado. El investigador joven se debe iniciar con temas sencillos utilizando materiales asequibles, hay muchos temas nacionales que resolver. (Cahuantico et al., 2010) Los temas complicados lo resolverán los países del Primer Mundo y los publicarán para su difusión.

Martin (2018) al inicio de su libro dice: El ser humano se pasa la vida haciéndose preguntas: ¿qué haremos en nuestro tiempo libre?, ¿veremos a los amigos?, ¿dónde iremos de vacaciones?, ¿encontraré trabajo?, ¿dónde habré dejado el teléfono?, ¿me quieres? El ser humano es un filósofo por naturaleza y, si se les ofrecen oportunidades, se hará preguntas en todas las edades y buscaran las respuestas.

Cuando se plantean preguntas se generan problemas intrascendentes o trascendentes, el primero es algo simple, el segundo para ser resueltos requiere de procesos especializados. En el primero las preguntas son de rutina como: ¿dónde está mi celular?, que se resuelve buscando en los lugares habituales gracias a las experiencias pasadas; para responder preguntas más puntuales se requieren métodos estandarizados.

No contando con un reloj, se pregunta la hora a quien lo tiene y el problema está resuelto. Si la pregunta es ¿por qué está cambiando el clima en ésta región?, los expertos deben buscar la respuesta mediante determinados procedimientos, tratando de lograr la respuesta contando con su experiencia y los elementos necesarios. 
Los resultados de una investigación se encuentran en el cuaderno de campo, en donde se anotó en forma secuencial todo lo que se logró. Para escribir el artículo, se requiere ordenar esa información de acuerdo a las instrucciones de la revista.

El orden que solicitan los editores para el artículo experimental.

01. Título

02. Autor(es)

03. Institución

04. Resumen

05. Introducción

06. Material y Métodos

07. Resultados

08. Discusión

09. Agradecimientos (opcional)

10. Referencias bibliográficas

Para no estar corrigiendo y re corrigiendo durante la redacción del artículo, se debe escribir siguiendo el siguiente método.

La información contenida en el cuaderno de campo, se escribe en el siguiente orden:

Sección

Lugar que ocupa en el artículo

01. Material y métodos

02. Resultados con tablas y/o figuras

03. Discusión

04. Introducción

05. Referencias bibliográficas

06 . Resumen con palabras clave

07 . agradecimientos

08. Autor(es)

09. Institución

10. Título

01. Se escribe lo relacionado con material y métodos que es el procedimiento que se utilizó para desarrollar la investigación, tomando la información que está en el cuaderno de campo. Redactada esta sección se imprime, se engrapan las hojas y se coloca en la parte superior derecha el número 06.

02. Siguiendo el procedimiento anterior, se escribe los resultados en texto detallado, en forma similar a como aparecen en los artículos de las revistas científicas. Si fuera necesario aclarar algún concepto de los resultados se preparan algunas tablas y/o figuras. Una vez impresa esta sección, se engrapa las hojas y se coloca el número 07 , se guarda encima del anterior.

03. En la Discusión se explica los resultados y se comparan con los resultados de algunas publicaciones que se consultó para la investigación, de aquí se obtienen las conclusiones y las recomendaciones si fuera el caso. Una vez impresa esta sección, se engrapa las hojas y se coloca el número 08 , se guarda con los anteriores.

Utilizando las informaciones anteriores se escribe la Introducción que es la presentación de la investigación.

04. Introducción, se coloca los antecedentes, el problema, la hipótesis y los objetivos ampliando los que figuran en el proyecto. Una vez impresa esta sección, se engrapa las hojas y se coloca el número 05 , se guarda con los anteriores

05. Referencias bibliográficas, es la información que utilizó el investigador. Escrita correctamente de acuerdo al estilo o norma que indica el editor de la revista en donde se pretende publicar. Una vez impresa esta sección, se engrapa las hojas y se coloca el número 10 , se guarda con los anteriores.

06. Resumen es el compendio de la investigación. Es la recapitulación del IMRyD. De preferencia estructurado con: Objetivos, métodos, resultados y conclusiones. Las palabras clave son palabras simples, compuestas si es 
su naturaleza; no oraciones cortas. Abstract con keywords. Una vez impresa esta sección se engrapa las hojas y se coloca en la parte superior derecha el número 04, se guarda con los anteriores.

07. Agradecimientos, si fuera necesario agradecer primero a las personas y después a las instituciones. Una vez impresa esta sección, se coloca el número 09, se guarda con los anteriores.

08. Nombre del autor(es) Nombres y apellidos del autor o los coautores. Una vez impresa esta sección, se coloca el número 02 , se guarda con los anteriores.

09. Institución. En donde se realizó la investigación. Una vez impresa esta sección, se coloca el número 03, se guarda con los anteriores

10. Título es el súper resumen de la investigación. En lo posible con 15 palabras. Una vez impresa esta sección, se coloca el número 01 , se guarda con los anteriores.

Terminada las impresiones, se ordena del 01 al 10 y se tiene la secuencia del artículo. Luego se debe revisar la sintaxis (Ishiyama, 2018), debido que la palabra impresa es eterna.

Investigar y publicar es una tarea sencilla cuando se eliminan los conceptos complicados creados por algunos autores de libros sobre metodología de la investigación, que son difundidos por sus seguidores. Cada autor expresa sus propias ideas, no hay dos libros sobre metodología de la investigación que se parezcan entre ellos en un buen porcentaje.

El profesor que dicta cursos de investigación lo debe hacer en forma sencilla con prácticas y asesoría constante, sin exagerar en definiciones y conceptos complicados; siguiendo el proceso sencillo para estimular a los jóvenes similar a como se iniciaron los pioneros de la investigación científica (De Kruif, s/f)

Las nuevas tecnologías para investigar son tantas que ha sobrepasado el entendimiento humano, tratar de aplicarlas todas, confunde; más aún, cuando quien dicta el curso no es investigador.

\section{La tesis como artículo}

En las universidades y los institutos superiores se sustentan tesis, las que después de ser aprobadas generalmente terminan en el estante de la biblioteca de la institución. La tesis le costó al graduando tiempo, dinero y esfuerzo, por lo que debería ser de conocimiento de la comunidad para ser utilizada por los de la especialidad.

La Ley Universitaria permite que cada universidad tenga su propio esquema y cada facultad la propia, por lo que el formato está atomizado; no establece un formato único para todas las universidades, la sustenta con "... se realiza de acuerdo a las exigencias académicas que cada universidad establezca en sus respectivas normas internas...", esto permite que cada institución tenga su propio reglamento.

En el pregrado, algunos docentes del curso Metodología de la Tesis complican la formación de los potenciales investigadores con cursos detallistas y memorísticos desde el proyecto, haciendo de algo sencillo un aprendizaje complicado sin prácticas, la práctica hace mejor a la persona, así como a su capacidad profesional. No enseñan cómo encontrar temas originales que existen en cantidades en el ambiente y en la literatura científica, ni a desarrollar la investigación con prácticas.

El investigador tiene la obligación ética, no solo de profundizar el saber sino en compartirlo para beneficio de la humanidad.

Para escribir la tesis en formato de artículo, se debe utilizar la tesis como cuaderno de campo en donde la información ya está pre ordenada. Siguiendo el método original descrito arriba, se escribe en el orden que solicitan los editores para el artículo experimental (Ishiyama, 2019)

Así de sencillo. 


\section{REFERENCIAS BIBLIOGRÁFICAS}

Cahuantico, L., Quispe T.G., Umeres, K., Meza,M., Huillca,Y., Ttito, A., Montúfar, D., \& Huilca, K. (2010). Potencial de uso ecoturístico y de biodiversidad del humedal de las comunidades de Chumo, Suyo y Mojonsuyo de Sicuani, Cusco. Gakushuu Kenkyuu. 2(1), 27-31. En: https://issuu.com/frankhamiltonlozadacuadros/docs/ vol2n1

De Kruif, P. (s/f). Los cazadores de microbios. Santiago: Ediciones Nueva Fénix. En: https://clea.edu.mx/biblioteca/Paul\%20de\%20Kruif\%20-\%20Cazadores\%20de\%20microbios.pdf En: http://librosmaravillosos.com/ cazadoresdemicrobios/index.html

Ishiyama, R. (2018). La equivocada creencia que iniciarse en la investigación científica es un proceso complicado. Revista Experiencia en Medicina. 4(1), 33-35. En: http://www.rem.hrlamb.gob.pe/index.php/REM/issue/ archive

Ishiyama, R. (2019). La tesis como artículo científico. Revista Experiencia en Medicina. 5(3), 151-152. En: http:// www.rem.hrlamb.gob.pe/index.php/REM/issue/archive

Martin, B. J. (2018). Cuestiones Filosóficas. Madrid: Editorial LIEBSA. En: https://www.agapea.com/Belen-Jacoba-Martin/Cuestiones-Filosoficas-Respuestas-de-los-Grandes-Pensadores-9788466237130-i.htm

Correo electrónico: raishiyama@yahoo.com 